\title{
The Impact of COVID-19 on the Academic Performance of Students: A Psychosocial Study Using Association and Regression Model
}

\author{
Aderonke B. Sakpere \\ Department of Computer Science, University of Ibadan, Nigeria \\ E-mail: ab.sakpere@ui.edu.ng
}

\section{Ayomiposi G. Oluwadebi}

Department of Geological Sciences, Osun State University, Nigeria

E-mail: ayofyfo@gmail.com

\author{
Oluwatoyin H. Ajilore \\ Department of Geology, University of Ibadan, Nigeria \\ E-mail: olutoyinajilore@gmail.com
}

\author{
Lauretta E. Malaka \\ Department of Agricultural and Environmental Engineering, University of Ibadan, Nigeria \\ E-mail: laurettaeloho@gmail.com
}

Received: 30 March 2021; Accepted: 04 July 2021; Published: 08 October 2021

\begin{abstract}
The novel coronavirus (COVID-19) has affected every sector of human activities. The outbreak has not only resulted in the risk of death from infection but has greatly affected the education system globally. While universities around the world have adapted to academic changes because of this pandemic, some other universities such as in Nigeria seem to be far behind. Therefore, this study aims to understand the impact of COVID-19 on students in higher institutions in Nigeria. The study utilizes an interactive survey design to get responses from 1533 respondents who are students of tertiary institutions. Two sampling techniques, namely snow-balling and purposive, are used to administer the questionnaire. The participants are representative samples from across the 6 geo-political zones of Nigeria. The results from the descriptive analysis reveals that $11.6 \%$ of the respondents have been able to continue school online and $41.4 \%$ have a level of doubt about the ability of their school can adapt to the learning mode occurring globally. Inferential analysis was carried out to understand the association and regression between variables. Results from ChiSquare Test of association show that students from public universities are economically more affected than those from private universities $(P$-value $<.005)$. The ordinal logistic model considered multiple independent variables. Results from the logistic model showed that the future effect of COVID-19 on career/academic progression of students hold, irrespective of discipline or degree of study or university category or level/year of study. Furthermore, $30 \%$ of the students, regardless of their discipline, degree of study, or university category expressed extreme or moderate hopelessness about their academic future concerning the pandemic.

The study has shown that the pandemic did not only lead to physical, technological, and economical challenges to education for Nigerian students, but also psychosocial challenges (such as hopelessness and high level of distrust for the existing educational systems) that may affect the way student engage and commit to their education in the postpandemic world. This provides educational stakeholders including policy makers the adequate data needed to understand how exactly students have been affected and supportive measure to implement as tertiary institutions reopen for learning.
\end{abstract}

Index Terms: COVID-19 Pandemic, Online Education, University Students, Lockdown, Physco-social Impact, Association Analysis, Ordinal Logistic Regression 


\section{Introduction}

The COVID-19 pandemic brought on its heel attendant difficulties in various sectors of human endeavor [1] when the City of Wuhan announced deaths caused by a deadly virus known as the Coronavirus in December 2019 [2]. Virtually, people of all age groups, nationalities, organizations and world economy were affected. The response in different nations has followed the general World Health Organization guidelines in March 2020, which included border closure, closure of schools and daycare, social distancing, maintaining basic hygiene, mobilization of medical personnel, facilities and equipment, creation of isolation centers, lockdowns and other restrictions of human and vehicular movements save for essential personnel and services. The consequences of the current pandemic have been enormous worldwide with a great impact on the educational system.

Education which is a major determinant of the quality of life and key in development [3] was particularly hit as it depends mostly on human interaction which was minimized as a means of curbing the COVID-19 spread. The outbreak, which was termed a pandemic by the World Health Organization (WHO) in March 2020 [4], disrupted the global educational system as most countries around the world implemented a closure of all educational institutions in an attempt to contain the spread of the pandemic [1,5,6]. According to the report by UNESCO (2020), the closures of schools and other learning spaces impacted 94 per cent of the world's student population, and up to 99 percent in low and lower-middle income [7].

Ogunode [8] predicted that the closure of all educational institutions would affect the students' academic plans and programme. While universities around the world, including some in Africa, have adapted to academic changes as a result of this pandemic, Nigeria seems to be far behind in providing alternative solutions especially for students of higher institutions. Only a few private tertiary institutions can leverage technology to continue their academic sessions. Adeoye et al. [9] identified poor budgetary allocation, corruption and government unpreparedness as contributing factors to the inability of many public tertiary institutions to embrace e-learning during the COVID-19 pandemic in Nigeria.

Some studies have been carried out on the effects of COVID-19 on education around the world. Upoalkapajor [10] conducted a study to assess the effects of COVID-19 on education in Ghana and concluded that the pandemic has a significant impact on education in Ghana and that schools require resources to reconstruct the loss in education through the pandemic. Adeyanju et al, [7] investigated the impact of the coronavirus pandemic on tertiary education in Nigeria and highlighted outstanding indigenous innovations within tertiary institutions prompted by the pandemic while providing useful information for University administrators and managers towards the development of a workable post COVID-19 education strategy and response plan.

Many of the existing studies addressed the question of the effects of COVID-19 mostly from the perspective of teachers, researchers, educational administrators and government bodies. Very few seek to study the effects of the pandemic on education from students' perspective. Students in tertiary institutions have every reason to be worried about the effects of the pandemic on their future. In a developing country like Nigeria, it is pertinent to understand the implication of the new normal on academic performance and emotional stability of students. Prior to the pandemic in Nigeria, public university students already had their learning halted due to university staff strike, and the pandemic with no vaccine in sight (as at the time of writing this paper) made return to learning almost impossible due to the unavailability of structures in place to aid online learning and easy access to data. While some private institutions were able to continue learning, a large percentage of students were unable to as teachers and students didn't have the requisite structures to learn in the case of such eventualities. For final year students, they faced the uncertainty of getting wellpaying job as they will be graduating (at an unknown date) in the middle of a recession. Thus, this study focuses on understanding the psycho-social impact of COVID-19 on students in Nigeria with a survey among respondents who are tertiary institution students. It also analyses students' reaction to the impact of the pandemic on issues such as parent finances, productivity, future prospect and adherence to COVID-19 protection guidelines (e.g. the availability of WASH facilities and handling class volumes) in the case of a return back to school.

We believe that the results of this study will help university leadership and policymakers to make urgent evidenceinformed recovery decisions when universities are finally reopen for learning.

The rest of this study is organized as follows: the reviewed related literature and discussion on the gap that still exists in the study of how - COVID-19 has affected education is reported in Section 2. Section 3 describes the methodology adopted in the study and collection of data. The detailed statistical analysis of collected data is reported in Section 4. Finally, Section 5 presents conclusion and future work.

\section{Previous Studies}

\subsection{Effects of Covid-19 on Global Education}

The COVID-19 pandemic brought on its heel attendant difficulties in various sectors of human endeavor. Education was particularly hit because of it established large dependence on in-person interaction which was 
minimalized to curb the community spread of COVID-19. Closure of schools and other physical learning spaces was observed in many countries which abruptly affected every form of onsite learning activity. According to UNESCO (2020) [11], the COVID-19 pandemic created the largest disruption of education systems in history, affecting nearly 1.6 billion students in more than 190 countries and in all continents. The closures of schools impacted 94 per cent of the world's student population, and up to 99 per cent in low and lower-middle income countries[11].

The pandemic has not been all gloomy as it also encouraged innovation in the education sector. As a result of necessity, several innovative approaches to support the continuity of education has been undertaken around the world. These range from remote/online learning to local and national use of radio and TV for widespread education and went as far as social media usage. Several governments, non-profits and global institutions partner together to bolster education against the crippling effects of the pandemic. These innovations have brought about several changes to the manner with which education is delivered around the world. However, these changes also heightened the awareness of the economic divide between various countries and continents and hence also highlighted that the future of learning and the accelerated changes in modes of delivering quality education, cannot be separated from the imperative of leaving no one behind [11]. A global study has also shown that the impact of the pandemic on students varies from one continent to another [12]. As a result, this study intend to dig deeper into how the pandemic has affected students in Africa (Nigeria) by taking various factors such as academic, social, economic, psychology and safety into consideration.

\subsection{Effects of COVID-19 on Students in the West}

COVID-19 brought about the closure of schools in most of the Western Countries. In the United States, vast majority of campuses, particularly those of large public and private universities, had already closed weeks before the government's intervention and state authorities mandated closure. In Europe, all classroom activities were already suspended by May 2020 [13] .

Control measures issued by the Western Governments varied widely from 15-30 days in mild cases whereas in severe cases, as observed in Spain and Italy, decisions were made to cease physical classes for the rest of the academic year by March 2020 [13]. However, in June 2020, the Spanish government experimented a new schooling system in preparation for resumption, using a few schools such as Colehio Virgien de Europa as case studies. The case study schools conducted physical classes with the students checked for fever at the school gate and mandated to wear face masks. Classes began and ended with thorough handwashing and disinfecting of desks and chairs. Students were only allowed to take their masks off in the classroom if they sat two meters apart. The same procedure also went for the teachers, who had to be previously tested and cleared of the virus [14]. With respect to the mental health well-being of students in the West, a number of study has established that the pandemic has negatively contributed to it [5,15-17]. A gap that is still yet to be extensively researched is how the pandemic affects the social and economic life of students. Our research intend to fill this gap. Furthermore, it is evident from this reviews that covid-19 pandemic has already brought remarkable changes in the way education is being done in the West. New strategies being deployed to allow for proper and safe education are also expected to bring new challenges and news gap for stakeholders to fill. The new challenges need to be adequately understood to be properly addressed. Delineating the shape of the new gaps associated with the impacts of COVID-19 on education, especially on students is the focus of this paper.

\subsection{Effects of COVID-19 on Students in Asia}

COVID-19 also led to the closure of schools on the Asian Continent. As the virus originated from the continent, the effect of the virus on education was swifter than other continents. Japan already announced school shutdown by February 18, 2020 for most education levels, at a time the first case of the virus had not been detected in some countries in the world [18]. Other countries such as China, Taiwan, Mongolia, Korea also shut down schools.

The pandemic resulted in the transition to online learning in many Asian countries. However, this came with a host of challenges for students who did not have access to reliable, fast, and affordable internet as digital inequalities exist within the continent. For example, countries like Singapore, Brunei, Malaysia have about $80 \%$ internet penetration whereas countries like Indonesia, Thailand and Cambodia have less than $60 \%$ internet penetration. Even lesser access to the internet (about 40\%) exists in countries like Myanmar and Vietnam [19].

Another important issue that plagued the transition to online learning in Asian communities is the preparedness of the students, teachers, institutional systems, and infrastructures. This also varied from country to country. As countries like the Republic of Korea recorded relatively higher ease in the area as the country already had significant internet and system infrastructure in place, countries like Indonesia, Philippines with lesser prepared systems struggled as the transition received mixed review from students [19-20]. In a survey of 1,045 students conducted by the Indonesia University of Education, $48 \%$ of students appeared to need more time to get used to internet-based learning, despite the availability of teaching applications [15]. In Philippines, the Commission on Higher Education had to suspend online mode of learning after students and teachers reacted against it [20]. These previous works also confirmed the assertion that the pandemic has brought new changes which in turn has brought new challenges to the academic activities in the new normal that need to be properly understood so that they can be adequately addressed. 


\subsection{Effects of COVID-19 on Students in Africa}

The effect of coronavirus in Africa seemed more severe than most of the other continents. School closure led to the temporary halt of educational activities in some countries in Africa [8] This can be attributed in part to acute digital divide in several countries on the continent, which made wholistic transition to online learning much more challenging. The situation has been feared to be capable of holding back education even further on a continent where more than 200 million children and adolescents were already not in school. In the West and Central African region, these nationwide closures are impacting 140 million children [21].

Governments and key education stakeholders have so far instituted urgent measures to ensure minimum disruption of learning due to the shutdown of schools. While these measures have gone some distance in promoting the continuity of education from home, it is yet to fully address the huge impacts of the pandemic on African education due to limitations such as inadequate infrastructure and online learning content, scarcity of needed resources, geographical location among others [21].

After the closure of schools in Africa's most populous country, Nigeria, in March 2020, the pandemic unmasked substantial inequities in the education sector. Students who could afford private education in schools that are able to provide online schooling continued learning while those from rural and underserved communities in many parts of the country were left behind [22]

The situation was not totally dismal as many countries in Africa adopted novel and innovative approaches to minimize the effect of COVID-19 on education and students. South Africa saw the pandemic as a wakeup call to further embrace the use of technology for teaching [23]. Countries such as Côte d'Ivoire, Morocco and Tunisia negotiated with mobile telecommunication providers to allow learners access online learning free of charge or at reduced rates, while Kenya, Morocco, Rwanda, and Zambia adopted a review system that guarded the quality assurance of education content promoted on private and public television channels. Morocco provided an "electronic listening device" via a toll-free mobile number and email address to support education stakeholders (students, teachers, and parents) [21].

\subsection{Literature Gaps existing in the study of the effects of COVID-19 on education and students}

Some studies have been carried out on the effects of COVID-19 on education in Africa. The focus of such studies includes the impact of COVID-19 on education in Ghana[10], innovative efforts of tertiary institutions in Nigeria towards curbing the virus [7], and the impact of COVID-19 on digital transformation of education in South Africa [23].

Many of the existing studies address the question of the effects of COVID-19 mostly from the perspective of teachers, researchers, educational administrators, and government bodies. Very few seek to study the effects of the pandemic on education from the vantage point of students, who are the major target group at the receiving end of every occurrence in the sector. In the face of such acute digital divide in a developing country like Nigeria, it is pertinent to understand what the new normal will mean for students. In addition, previous works have begun to show that education has been remarkably impacted by the pandemic causing a rethink in the manner in which the teaching, learning and other academic activities are being done. Seeing that quite a number of these changes have probably come to stay as the world still grapples with the pandemic and its effect, and that the changes are going to ring about new challenges, this study seeks to understand the effects of COVID-19 on education in Nigeria from the perspective of tertiary institution students. The work is aimed at unravelling the new challenges that has been uncovered as a result of the pandemic to help stakeholders understand how to address the matter of providing appropriate education in the new normal.

\section{Material and Method}

\subsection{Survey Design}

The study used structured questionnaires to collect data that would assess the psychosocial effect of COVID-19 on Nigerian students. The Generalized Anxiety Disorder Scale/calculator was adapted in the design of the questionnaire. Inspiration was also drawn from the COVID-19 scale fear developed by a recent study [24]. In addition, questions were designed to capture the impact of the pandemic on issues such as finances, productivity, future prospect and adherence to COVID-19 protection guidelines. Table 1 shows some of the study measuring instruments. Most item was measured using a 5-Likert scale. Table 1 which is the study measurement instrument was inspired and designed based on standards used for measuring emotional imbalance (Anxiety, Depression) [25, 26] and COVID-19 impact scale [24], [27]. In addition, after the design of our questionnaire, a pilot study was conducted to validate the usability and applicability of the survey instrument with participants drawn from experts in Human Computer Interaction, Education Discipline and Questionnaire Design. A fraction of the targeted participants was also included in the pilot study. Review from the pilot study was used to further improve the design of the measuring instrument before final deployment and administration. Details of the pilot study and the validity/suitability of the measuring instrument is published in [28].

Online Google Forms were used to administer the survey. The survey was designed to ensure data confidentiality and reliability. The survey consists of 24 questions and was developed in such a way that respondents could enter a response by clicking on a 'select a response drop-down box' and then choose one of the answer options. A drop-down 
box saves time and encourages the participant because they do not need to spend time in writing their responses. The survey was 4 pages long and designed such that it could easily be completed by clicking the suitable responses. Once the submit button was clicked; completed surveys were received by us (the researchers). It was designed also with some GIFs to provide a relaxing, fun and interactive environment that can bring out honest responses from the participants. Additionally, the survey was translated from English Language Version to Pidgin Language Version and either of the 2 language versions was filled depending on the respondent's choice. Pidgin English is an informal/local language commonly spoken in Nigeria.

Table 1. Study's measurement instruments.

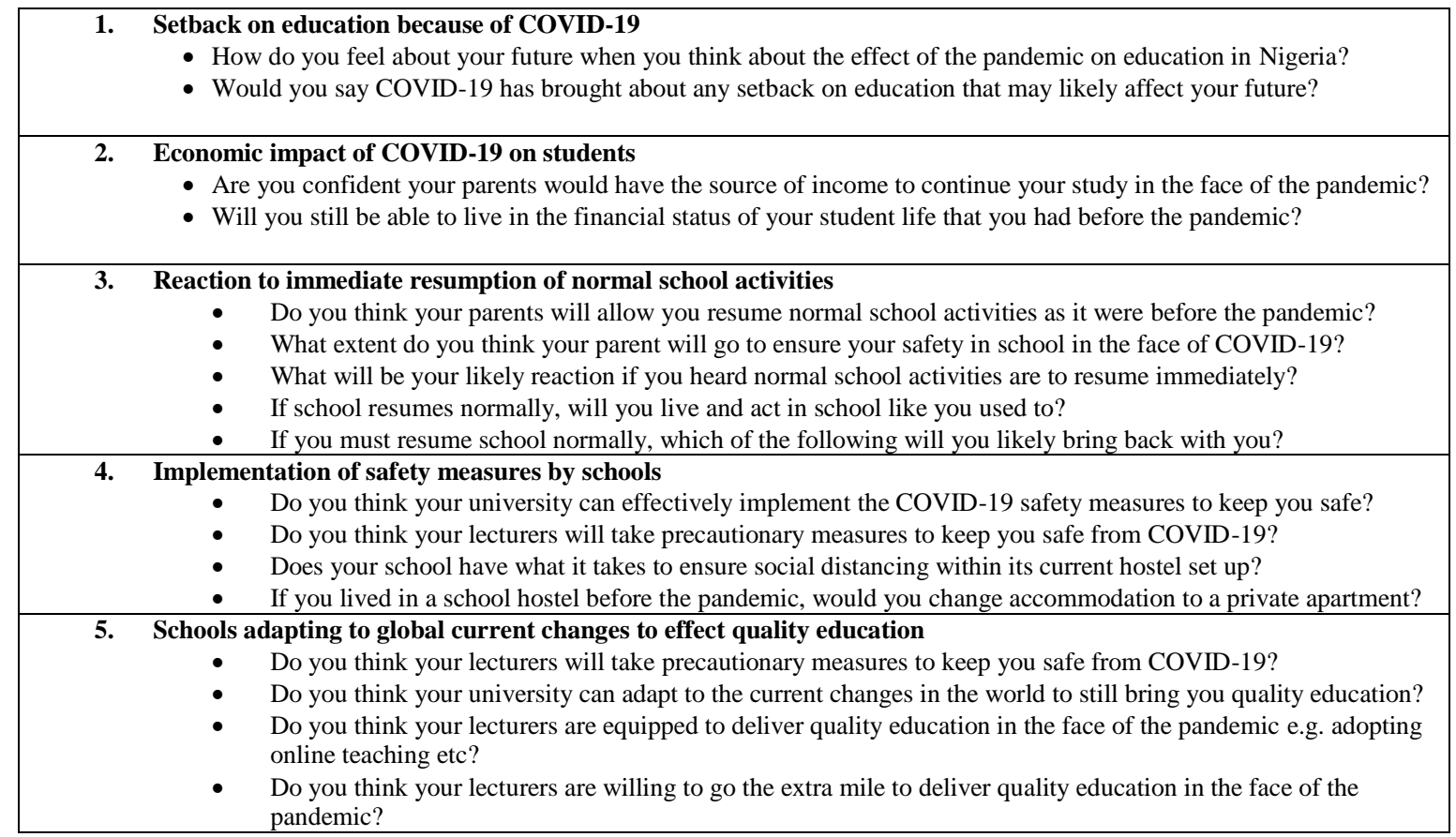

\subsection{The Participants}

The target population for the study comprises of students from the tertiary institutions of Nigeria. This includes students from various universities, polytechnics, and colleges of education in public and private institutions. Two sampling techniques namely snow-balling and purposive were used. Snow-balling technique was adopted in order to leverage on the network of colleagues and was augmented by purposive technique in order to reach all the Geopolitical zones in Nigeria. As a result, our sample is drawn from the six geo-political zones of the country, namely South-West, North Central, North West and North East, South-South and South-East. This is important so as to have a full representative of the entire country. The study sample size was 1,533 respondents (1,267 from English Version and 266 from Pidgin Version).

\subsection{Data Collection}

The survey was posted online from July 19 through September 2, 2020, using diverse electronic means such as Email and various social media platforms (LinkedIn, WhatsApp, and Facebook). The study collected data on students' demographics and questions related to psychosocial factors, the students' current experiences about the pandemic and their future academic expectations. . In order to ensure we have a fair representation and distribution in our data collection, participants were recruited from various categories of higher institutions in Nigeria - Private Universities and Public Universities. Typically, the private universities are owned and managed by individuals or private organizations while the public universities are owned by Government (State or Federal).

\subsection{Survey Model}

Modelling gives a better understanding of a problem domain and has been used in the context of developing world [29]. As a result, it is adopted in this work to help model impact of COVID-19 on students in the developing world. Regression model in general attempts to find answers to two questions. First, the relationship between two variables. Then, prediction of one variable given the other [30]. Regression models are in various forms - linear (simple, multiple) and logistic (ordinal, multinomial). Linear regressions are applicable when the dependent/independent variables have their values in interval or ratio. On the other hand, logistic regressions are appropriate when the dependent variable is dichotomous (binary). While the dependent variable is classified according to their order of magnitude, one cannot use the multinomial logistic regression model [31]. Since our interest in this research is classified according to order of 
magnitude (through the adoption of Likert scale), it therefore makes ordinal logistic regression the best model to be adopted. The response of interest in the survey is the attribute 'Future Affected (FA) and Financial Strength (FS)' variables. These variables use a 5-likert scale to measure the severity level in an order of magnitude, from very severe to less severe. Furthermore, we adopted CHI Test of Association. CHI Test of association measures relationship/association between two variables. This association can be modelled as an $\mathrm{m} \times \mathrm{n}$ matrix where $\mathrm{m}$ which is the row represents the dependent variable and $n$ which is the column represents the response variable of interest. This matrix is illustrated in equation 1 .

$$
\left(\begin{array}{cccc}
a_{11} & a_{12} & \ldots & a_{1 n} \\
a_{21} & a_{22} & \ldots & a_{2 n} \\
: & : & : & : \\
a_{m 1} & a_{m 2} & \ldots & a_{m n}
\end{array}\right)
$$

Ordinal Logistic Regression is used to predict an ordinal dependent variable given one or more independent variables [32]. In our case, we would like to predict if independent variables such as discipline, University Category/attended have effect on the dependent variable, future of a student affected, even in the midst of the COVID19 pandemic/lockdown. To model the ordinal logistic regression, consider a set of $\mathrm{m}$ independent variables (discipline, level of study); $\mathbf{X}=\left\{\mathrm{X}_{1}, \mathrm{X}_{2}, \ldots, \mathrm{X}_{\mathrm{m}}\right\}$ and a response variable $\mathbf{Y}=\left\{\mathrm{Y}_{1}, \mathrm{Y}_{2}, \ldots, \mathrm{X}_{\mathrm{n}}\right\}$. Our response variable is a positive integer on a scale of $\mathrm{k}$ from which the ordinal dependent variable draws value. Let us also assume that each set of observations, $x_{i}=\left\{x_{i 1}, x_{i 2}, \ldots, x_{i m}\right\}$ corresponds to measurement collected by a subject $i$.

The total log likelihood is a sum of contributions from each of the observations:

$$
\mathrm{L}(\pi ; \mathrm{y})=\Sigma \mathrm{i} \mathrm{L}(\pi \mathrm{i} ; \mathrm{yi})
$$

$\pi_{i k}$ probability of the $i^{\text {th }}$ observation for the $k^{\text {th }}$ category

\section{Results and Discussion}

Excel Spreadsheet and a data analysis software package named Minitab, version 19 (64-bit) were used for analysis. In this section, our result is divided into descriptive statistical analysis and inferential statistics analysis.

\subsection{Descriptive Statistical Analysis}

The data obtained from the questionnaire were analyzed descriptively and the summary is presented in Table $1-5$. The descriptive analysis shows information such as demography of the respondents, students' engagement since lockdown, effect of the pandemic, students' judgment of lecturers and universities/governments ability to adapt to global practice of teaching amid the pandemic and willingness to adapt to COVID-19 safety guidelines.

The participants were drawn from student population across all the 6 geographical/geo-political zones of Nigeria and their demographic information is shown on table 1 . Their participation was voluntary; hence no incentives were given to them. Overall, $49.4 \%$ of the 1533 participants are males and $49.7 \%$ are females. With regards to degree of study, $2.1 \%$ are doctoral students, $13.9 \%$ are masters/postgraduate students and $84.9 \%$ are undergraduate students.

Table 2. Demographic Information of Respondents

\begin{tabular}{|l|l|l|l|l|l|l|}
\hline & Numbers & $\%$ & Numbers & $\%$ & Numbers & $\%$ \\
\hline & \multicolumn{2}{|l|}{ English Responses } & \multicolumn{2}{l|}{ Pidgin Responses } & \multicolumn{2}{l|}{ Total (English + Pidgin) } \\
\hline Sex & & & & & & \\
\hline Female & 634 & 50.0 & 128 & 48.1 & 762 & 49.7 \\
\hline Male & 623 & 49.2 & 134 & 50.4 & 757 & 49.4 \\
\hline Prefer not to say & 10 & 0.8 & 4 & 1.5 & 14 & 0.9 \\
\hline Study level & & & & & & \\
\hline Doctoral & 30 & 2.4 & 2 & 0.8 & 32 & 2.1 \\
\hline Postgraduate & 171 & 13.5 & 42 & 15.8 & 213 & 13.9 \\
\hline Undergraduate & 1066 & 84.1 & 222 & 83.5 & 1288 & 84.0 \\
\hline
\end{tabular}

\subsubsection{Students Engagement in Lockdown}

Table 2 shows that $22.1 \%$ of the students have been up to nothing since the lockdown began. This result is close to that of a similar study that reported a zero-productivity of $14.8 \%$ among students and non-students population examined in Nigeria [27]. Further asking about their reaction to resuming back to school, over $40 \%$ reported that they would be 
excited and over $20 \%$ responded that they would be worried. This implies that as much as many students are excited to resume back, there are still about one-fifth that have one form of worry or the other about school resumption amid the ongoing pandemic. Likewise, a study carried out in China reported that over $20 \%$ of college students experienced anxiety because of the COVID-19 outbreak [33]. We can therefore establish that being worried or anxious about the pandemic is not only peculiar to students in Nigeria or Africa.

Table 3. Engagement during Lockdown

\begin{tabular}{|c|c|c|c|c|c|c|}
\hline & Numbers & $\%$ & Numbers & $\%$ & Numbers & $\%$ \\
\hline & \multicolumn{2}{|c|}{ English Responses } & \multicolumn{2}{|c|}{ Pidgin Responses } & \multicolumn{2}{|c|}{ Total (English + Pidgin) } \\
\hline \multicolumn{7}{|l|}{ Engagement since lockdown } \\
\hline Absolutely nothing & 272 & 21.5 & 67 & 25.2 & 339 & 22.1 \\
\hline Community service & 91 & 7.2 & 10 & 3.8 & 101 & 6.6 \\
\hline Continued my school classes online & 140 & 11.0 & 34 & 12.8 & 178 & 11.6 \\
\hline Freelancing & 255 & 20.1 & 65 & 24.4 & 320 & 20.9 \\
\hline Taking online courses & 253 & 20.0 & 26 & 9.8 & 279 & 18.2 \\
\hline Others (choice of 2 or more of above options) & & & & & 316 & 20.6 \\
\hline \multicolumn{7}{|l|}{$\begin{array}{l}\text { Reaction to immediate resumption of normal } \\
\text { school activities }\end{array}$} \\
\hline Angry & 37 & 2.9 & - & - & 37 & 2.9 \\
\hline Excited & 553 & 43.6 & - & - & 553 & 43.6 \\
\hline Indifferent & 251 & 19.8 & - & - & 251 & 19.8 \\
\hline Shocked & 180 & 14.2 & - & - & 180 & 14.2 \\
\hline Worried & 246 & 19.4 & - & - & 246 & 19.4 \\
\hline
\end{tabular}

\subsubsection{Setback on Education}

About $60 \%$ responded that COVID-19 has brought about one form of setback or the other to their education. One of the major reasons for this setback is because many of the higher institutions in Nigeria were totally lockdown with little or no support for online teaching. So, for most students in Nigeria, lectures/classes stopped during the lock down. Only few universities continued their classes online. Moreover, the Federal Government owned Institutions were on industrial strike. Our analysis from Table 2 confirms the lack of engagement as only $17.5 \%$ responded to have continued their classes/lectures online. This figure is low when compared to developed nations like USA, China where vast majority of their lectures continued online in the midst of the pandemic. Previous study in Africa has shown how the use of social media tools which is commonly available can be adapted for virtual/remote learning [34]. This implies that in the short-term, social media can be leveraged on for teaching in the developing world at little or no cost. On the long run, investments can be made into robust virtual facilities and learning management system. However, care must be taken in the design and adoption of the learning platform/tool as previous studies have shown that LMS/educational technology has faced objection, stereotype and low involvement in Africa [35,36]. A major reason for this objection is because most often technologies from the west are often adopted by major stakeholders without taking the peculiarity of the environment of adoption and end-users into consideration. For instance, a recent study has shown how many youths (university students) are addicted to technology/mobile phones in Africa [25]. As a result, these calls for designing solutions for students in Africa that would help promote a total well-being even while learning using technology.

Table 4. Setback on Education

\begin{tabular}{|c|c|c|c|c|c|c|}
\hline & Numbers & $\%$ & Numbers & $\%$ & Numbers & $\%$ \\
\hline & \multicolumn{2}{|c|}{ English Responses } & \multicolumn{2}{|c|}{ Pidgin Responses } & \multicolumn{2}{|c|}{ Total (English + Pidgin) } \\
\hline \multicolumn{7}{|c|}{$\begin{array}{l}\text { Setback on education because of } \\
\text { COVID-19. }\end{array}$} \\
\hline A little & 259 & 20.4 & 84 & 31.6 & 343 & 22.4 \\
\hline I don't know & 57 & 4.5 & 24 & 9.0 & 81 & 5.3 \\
\hline Maybe & 190 & 15.0 & 42 & 15.8 & 232 & 15.1 \\
\hline Nope & 209 & 16.5 & 105 & 39.5 & 314 & 20.5 \\
\hline Yes & 552 & 43.6 & 11 & 4.1 & 563 & 36.7 \\
\hline
\end{tabular}

\subsubsection{Adaptation to new learning mode}

Table 4 shows the level of trust that the students have in their school/country to switch to the new learning mode of online teaching even in the midst of covid-19 pandemic and lock down. From literature [34-35], many countries in 
Africa have not fully adopted the use of technology or Learning Management System (LMS) to facilitate teaching even before the pandemic or lockdown. So, in our research, we were curious to find how out how easy the students perceived that schools and their lecturers would adapt to this new learning mode. $22.3 \%$ of the respondents have an absolute believe that their schools/lecturers would easily adapt to this new learning mode. Also, $22.3 \%$ have firm believe that their lecturers are equipped to adapt to this change. This implies that over $70 \%$ of the respondents either do not believe or have an iota of doubt about the ability of their lecturers/school to adopt online teaching. An implication of this response could be that a lot of institutions in Nigeria are not well equipped with state of art technologies that can facilitate learning even in the nearest future. In similar researches conducted in Asia (India), the digital incompetence of teachers was also noted [37] and the technical difficulties teachers/lecturers face especially during covid-19 to use online platforms for instruction delivery and e-content creation [38]. This calls for more research in the space of educational technology in Nigeria, Africa and the world at large. In addition, there is also the need for academic institutions in Nigeria to consistently expose their academics to new digital skills and pedagogy techniques.

Table 5. Adaptation to new Learning Mode

\begin{tabular}{|c|c|c|c|c|c|c|}
\hline \multirow{3}{*}{$\begin{array}{l} \\
\begin{array}{l}\text { Schools adapting to global current } \\
\text { changes to effect quality education }\end{array}\end{array}$} & Numbers & $\%$ & Numbers & $\%$ & Numbers & $\%$ \\
\hline & \multicolumn{2}{|c|}{ English Responses } & \multicolumn{2}{|c|}{ Pidgin Responses } & \multicolumn{2}{|c|}{ Total (English + Pidgin) } \\
\hline & & & & & & \\
\hline Definitely & 310 & 24.5 & 32 & 12.0 & 342 & 22.3 \\
\hline Hell no! & 138 & 10.9 & 42 & 15.8 & 180 & 11.7 \\
\hline I don't know & 146 & 11.5 & 31 & 11.7 & 177 & 11.5 \\
\hline Maybe & 217 & 17.1 & 62 & 23.3 & 279 & 18.2 \\
\hline They'll try & 456 & 36.0 & 99 & 37.2 & 555 & 36.2 \\
\hline \multicolumn{7}{|c|}{$\begin{array}{l}\text { Implementation of safety measures } \\
\text { by schools }\end{array}$} \\
\hline Definitely & 291 & 23.0 & 22 & 8.3 & 313 & 20.4 \\
\hline Hell no! & 231 & 18.2 & 73 & 27.4 & 304 & 19.6 \\
\hline I don't know & 138 & 10.9 & 10 & 3.8 & 148 & 9.7 \\
\hline Maybe & 180 & 14.2 & - & - & 180 & 11.7 \\
\hline They'll try & 426 & 33.6 & 161 & 60.5 & 587 & 38.3 \\
\hline \multicolumn{7}{|c|}{$\begin{array}{l}\text { Lecturers equipped to deliver quality } \\
\text { education amidst pandemic }\end{array}$} \\
\hline Definitely & 303 & 23.9 & 32 & 12.0 & 335 & 22.3 \\
\hline Hell no! & 252 & 19.9 & 79 & 29.7 & 331 & 22.0 \\
\hline I don't know & 169 & 13.3 & 43 & 16.2 & 212 & 14.1 \\
\hline Maybe & 181 & 14.3 & - & - & 181 & 12.0 \\
\hline They'll figure something o & 361 & 28.5 & 94 & 35.3 & 445 & 29.6 \\
\hline \multicolumn{7}{|c|}{$\begin{array}{l}\text { Lecturer's willingness to go extra } \\
\text { mile to deliver quality education } \\
\text { amidst pandemic }\end{array}$} \\
\hline Definitely & 282 & 22.3 & 113 & 42.5 & 395 & 25.8 \\
\hline Hell no! & 158 & 12.5 & 55 & 20.7 & 213 & 13.9 \\
\hline I don't know & 182 & 14.4 & 44 & 16.5 & 226 & 14.7 \\
\hline Maybe & 216 & 17.0 & - & - & 216 & 14.1 \\
\hline They'll make some effort & 429 & 33.9 & 54 & 20.3 & 483 & 31.5 \\
\hline
\end{tabular}

\subsection{Inferential Statistical Analysis}

In order to understand the association that exists between different response variables and independent variables, advanced statistical models were used. The models used are Chi-Square Test for Association and Ordinal Logistic Regression. These models were used because they are best suited for measuring association among categorical/rank variables. Chi-square is a test for association or relationship between two categorical variables [30, 38]. Ordinal Logistic Regression models the relationship between a set of predictors or independent variables and an ordinal (ranked) response [40]. 


\subsubsection{Economic Effect of COVID-19 pandemic on Students}

Studies have suggested that remuneration or income affects people's productivity or ability to work during the COVID-19 pandemic [27] and global poverty level would likely increase for the first time since 1990 [41]. As a result, our study investigates the economic impact of COVID-19 on students. In order to measure this, respondents (students) were asked to rate the financial strength of their parents or sponsors on a scale of 1-5 in ascending order. Chi-Square Test of association was used to identify relationships between the response variable (financial strength) and independent variable (University Category). In Nigeria, Universities/tertiary institutions are either Public (Government Owned) or Private (Individual or Organization owned). Typically, private-owned universities in Nigeria are very expensive and mostly affordable by the rich (high-income earner) or the highly rated middle-income earner while public or Government owned universities are relatively cheap and attended by students whose parents are low or middle-income earners.

Table 2 and 3 are the results of the Chi-Test measure of the association between university category and financial strength. Table 2 shows the relationship while table 3 shows the $p$-values. Statistically, p-values often determine if the association between two variables is significant or not. If the $p$-value is less than or equal to 0.05 , then the conclusion is that there is a statistically significant association between the variables [25, 27, 30]. From Table 3 , the p-values are less than 0.05 ; therefore, we conclude that there is significant relationship between university category and financial strength. This significance is explained in Table 2. From Table 2, we can see that students in public universities have been very adversely affected financially compared to those in private institutions. Also, it can be seen that private universities were expected to be adversely affected by a count of 19.09 which is a wide deviation from the observed count of 6 . This implies that irrespective of the economic impact of COVID-19 pandemic, a lot of students in private institutions wouldn't find it very difficult to resume school or continue their education while a good number of students in public institutions would find it very difficult to resume back to school. On the bright side, both institutions have the highest prediction or count for the middle-rank (scale 3). We can therefore conclude that students in both private and public institutions have been somewhat severely affected with respect to their financial strength but those in public institutions are more affected. This stands to reason given the fact that a lot of the students in private institutions have wealthy parents who, even though might have been affected, could still possibly cope. On the other hand, a number of students in public universities who might manage to resume school might struggle to cope academically especially if learning would be virtual since this would require more financial obligations - the purchase of devices and internet data to support learning.

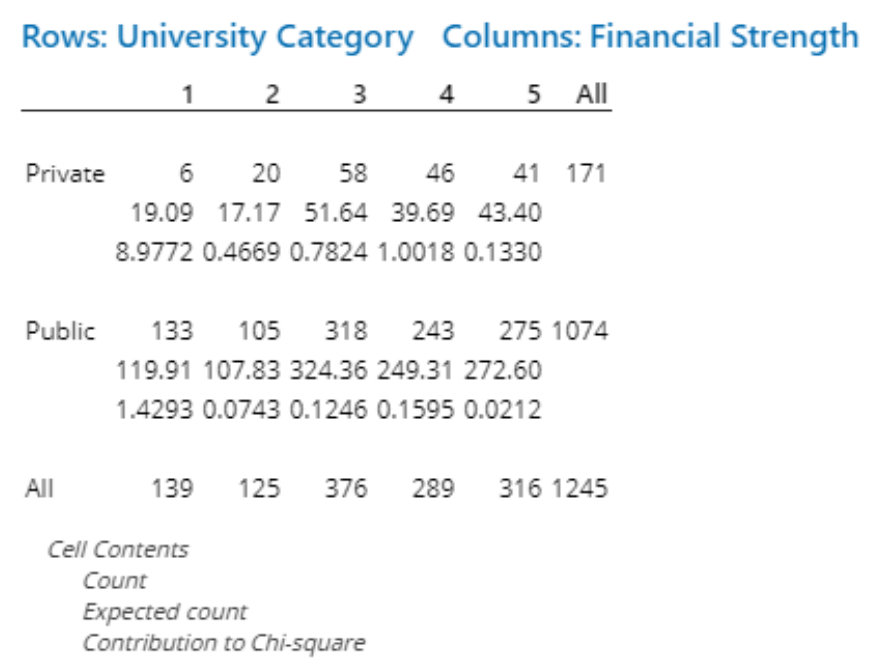

Fig.1. Summary of the Chi-Square Test of Association between University Category and Financial Strength

\section{Chi-Square Test}

\begin{tabular}{rrr}
\multicolumn{4}{c}{ Chi-Square DF P-Value } \\
\hline Pearson 13.170 & 4 & 0.010 \\
Likelihood Ratio 16.339 & 4 & 0.003
\end{tabular}

Fig.2. P-value analysis of Financial Strength Measure 


\subsubsection{Inferential Measure of Setback on education}

The next association we are interested in is to study how COVID-19 has affected or would affect students' future career progress. In other words, we are interested to know how COVID-19 has brought about or would bring about a set-back in their education. In order to determine how students' academic future would be affected or has been affected, a response variable, future affected, was defined. We therefore used ordinal logistic regression to see if there exists any statistically significant relationship between the response variable, future affected, and various independent variables such as discipline, level, degree of study and university category. Ordinal logistic regression works on categorical and multiple variables [32], [40].

Table 4 shows the summary of rating of how COVID-19 has affected/would affect the future of the students. The rating is done on scale of 5 , with 1 been extremely hopeful and 5 been extremely hopeless. Over $30 \%$ responded that they are either moderately or extremely hopeless about their future. Table 5 shows the result of the Ordinal Logistic Regression and various $p$-values of each independent variable. It can be seen that all the $p$-values are greater than the threshold of 0.05 . Since $p$-value is a determinant of significance of association between response variable and independent variables, we can conclude that the multiple independent variables (discipline, level, degree and university category) have no statistically significant relationship or effect on how students' future are affected. This implies that the future effect of COVID-19 on students hold irrespective of discipline or degree of study or university category or level/year of study.

Table 6. Categorical rating of how COVID-19 would has affected respondents' future

\begin{tabular}{ccc} 
Variable & Value & Count \\
\hline Future Affected? & 1 & 258 \\
& 2 & 382 \\
& 3 & 238 \\
& 4 & 256 \\
& 5 & 160 \\
& Total & 1294
\end{tabular}

Table 7. Ordinal Logistic Regression: Future Affected? Versus University Category, Discipline, Level

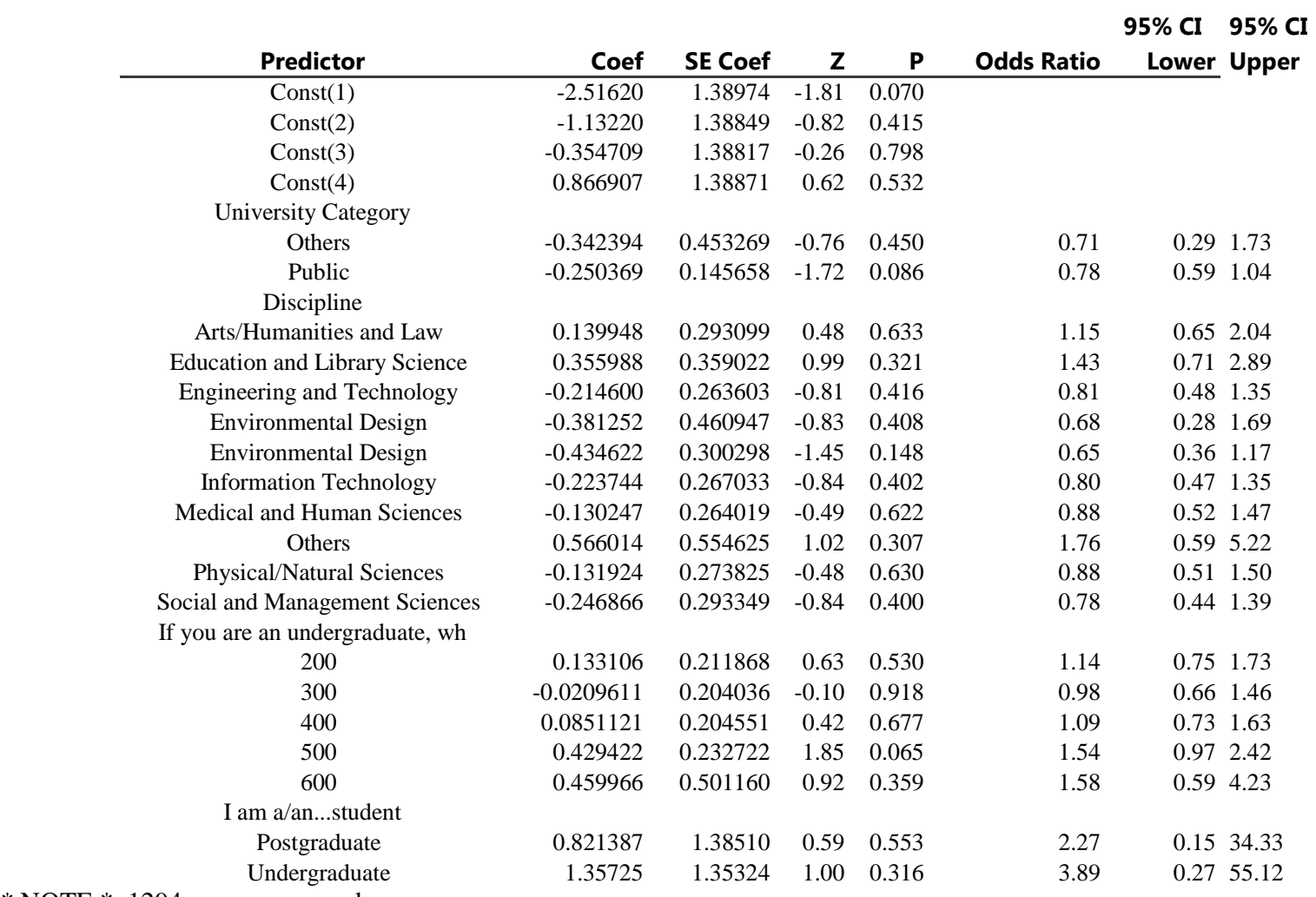

* NOTE *: 1294 cases were used

239 cases contained missing values or was a case with zero frequency. 


\subsubsection{Implications}

Our major results have revealed that students in public-owned universities are more economically affected by the impact of COVID-19 compared to those in Private-owned universities. Secondly, students from all disciplines and universities would likely experience a form of setback in their education. To resolve this, we recommend that government or organizations such as telecommunication, financial come to the aid of students in public owned universities who have been economically and academically affected. Many western countries have provided a form of incentives to help those who have been affected by the pandemic. As a result, we recommend that the Nigerian Government and other African countries provide appropriate incentives using the results uncovered in this study.

Secondly, we suggest that the government also provides more opportunities for students to be self-sustained or at least be able to fend for themselves in addition to what their parents can do. That can be done either by paying more attention to entrepreneurial education in the tertiary education system (many schools are already doing this, but it is mostly solo-work and not a systemic widespread change yet) or by finding ways to incorporate a work-study scheme into tertiary education plans like it is done in the Western World.

\section{Conclusion and Future Work}

The COVID-19 pandemic dealt a huge blow on the education sector across the world, with severe impact in Africa. Many studies have examined the level of this impact; however limited studies are from the vantage point of the students who constitute the major target group at the receiving end of every occurrence in the sector. Also, the impact of the pandemic on how education is being done in several areas of the world is expected to bring about new challenges and new gaps for education stakeholders to fill in the work of providing quality and affordable education. However, limited studies have sought to delineate the shape of the gaps and the actual nature of these challenges, especially as they affect students - psychologically, economically, future prospects and trust in stakeholders.

The study therefore explored the effects of COVID-19 on students in Africa by utilizing the case study of 1533 tertiary institution students of diverse university category, levels, degree of study and who are spread across the six geopolitical zones of Nigeria. Results showed that the economic impact of the COVID-19 pandemic, despite its widespread effects, has varying intensity on students depending on their university category (public-owned or privateowned). This inferentially leads to varying degrees of possible difficulty of students' education resumption as a result of university category.

Furthermore, the pandemic was characterized by low productivity and high anxiety among students. Six in every ten believe that the pandemic has brought about remarked setback in their education. $30 \%$ of the students, regardless of their discipline, degree of study, or university category expressed extreme or moderate hopelessness about their academic future in relation to the pandemic. Seven in every ten students have some level of distrust in the ability of their institutions to successfully transition to quality virtual education.

This work has thus advanced the state of knowledge of the impact of COVID-19 on education by lucidly detailing how the pandemic has affected student's learning, productivity and hope of the future of their education. The study has shown that the pandemic did not only lead to physical, technological, and economical challenges to education for Nigerian students, but also psychosocial challenges (such as hopelessness and high level of distrust for the existing educational systems) that may affect the way student engage and commit to their education in the post-pandemic world. This provides educational stakeholders including policy makers the adequate data needed to understand how exactly students have been affected and what to do to support students through post-pandemic education.

For future work, we would like to study how the universities physical facilities can support onsite resumption of students without violating the safety guidelines of COVID-19.

\section{References}

[1] D. Koh, "COVID-19 lockdowns throughout the world," Occupational Medicine, vol. 70, 2020, doi: 10.1093/occmed/kqaa073.

[2] Y. Yang et al., "The deadly coronaviruses: The 2003 SARS pandemic and the 2020 novel coronavirus epidemic in China," Journal of Autoimmunity, vol. 109, no. 102434, 2020, doi: 10.1016/j.jaut.2020.102434.

[3] L. O. Odia and S. I. Omofonmwan, "Educational System in Nigeria Problems and Prospects," Journal of Social Sciences, vol. 14, no. 1, 2007, doi: 10.1080/09718923.2007.11978347.

[4] N. Jebril, "World Health Organization Declared a Pandemic Public Health Menace: A Systematic Review of the Coronavirus Disease 2019 'COVID-19,'” SSRN Electronic Journal, 2020, doi: 10.2139/ssrn.3566298.

[5] P. Odriozola-González, Á. Planchuelo-Gómez, M. J. Irurtia, and R. de Luis-García, "Psychological effects of the COVID-19 outbreak and lockdown among students and workers of a Spanish university," Psychiatry Research, vol. 290, no. 113108, 2020, doi: 10.1016/j.psychres.2020.113108.

[6] S. Burgess and H. H. Sievertsen, "Schools, skills, and learning: The impact of COVID-19 on education," VoxEu., 2020. https://voxeu.org/article/impact-covid-19-education (accessed May 09, 2021).

[7] S. Adeyanju, O. H. Ajilore, O. Ogunlalu, A. Onatunji, and E. Mogaji, "Innovating in the face of the pandemic: Case studies from Nigerian Universities.," 2020. [Online]. Available: 
https://www.researchgate.net/publication/343774545_Innovating_in_the_face_of_the_Coronavirus_Covid19_pandemic_Case_studies_from_Nigerian_Universities.

[8] N. J. Ogunode, I. Abigeal, and A. E. Lydia, "Impact of COVID-19 on the Higher Institutions Development in Nigeria," Electronic Research Journal of Social Sciences and Humanities, vol. 2, no. 2, pp. 126-135, 2020.

[9] I. A. Adeoye, A. F. Adanikin, and A. Adanikin, "COVID-19 and E-Learning: Nigeria Tertiary Education System Experience," International Journal of Research and Innovation in Applied Science (IJRIAS) |, vol. 5, no. 5, pp. 28-31, 2020.

[10] J.-L. N. Upoalkpajor and C. B. Upoalkpajor, "The Impact of COVID-19 on Education in Ghana," Asian Journal of Education and Social Studies, pp. 23-33, 2020, doi: 10.9734/ajess/2020/v9i130238.

[11] UNESCO, "Policy Brief: Education during COVID-19 and beyond.," 2020. [Online]. Available: https://www.un.org/development/desa/dspd/wp-content/uploads/sites/22/2020/08/sg_policy_brief_covid19_and_education_august_2020.pdf.

[12] A. Aristovnik, D. Keržič, D. Ravšelj, N. Tomaževič, and L. Umek, "Impacts of the COVID-19 pandemic on life of higher education students: A global perspective," Sustainability (Switzerland), vol. 12, no. 20, 2020, doi: 10.3390/su12208438.

[13] UNESCO, "COVID-19 and higher education: Today and tomorrow," 2020. [Online]. Available: http://www.iesalc.unesco.org/en/wp-content/uploads/2020/04/COVID-19-EN-090420-2.pdf.

[14] H. Regan and S. George, "June 16 Coronavirus News," 2020. https://edition.cnn.com/world/live-news/coronavirus-pandemic06-16-20-intl/h_16f895d4b49f8d1be3dd02c2db66e8da.

[15] S. Marelli et al., "Impact of COVID-19 lockdown on sleep quality in university students and administration staff," Journal of Neurology, vol. 268, pp. 8-15, 2021, doi: 10.1007/s00415-020-10056-6.

[16] A. Patelarou et al., "Nursing students, mental health status during COVID-19 quarantine: evidence from three European countries," Journal of Mental Health, 2021, doi: 10.1080/09638237.2021.1875420.

[17] C. K. Kaparounaki, M. E. Patsali, D. P. V. Mousa, E. V. K. Papadopoulou, K. K. K. Papadopoulou, and K. N. Fountoulakis, "University students' mental health amidst the COVID-19 quarantine in Greece," Psychiatry Research, vol. 290, 2020, doi: 10.1016/j.psychres.2020.113111.

[18] M. Okajima, "The impact of COVID-19 on society in the Asia-Pacific region," 2020. https://www.ei-ie.org/en/item/23341:theimpact-of-covid-19-on-society-in-the-asia-pacific-region-by-masaki-okajima.

[19] N. Yarrow, "COVID-19 in East Asia: How the Region's Higher Education Systems are Addressing the Crisis to Adapt to the Future.le,” 2020. https://blogs.worldbank.org/education/covid-19-east-asia-how-regions-higher-education-systems-areaddressing-crisis-adapt.

[20] C. M. Toquero, "Challenges and Opportunities for Higher Education amid the COVID-19 Pandemic: The Philippine Context," Pedagogical Research, vol. 5, no. 4, 2020, doi: 10.29333/pr/7947.

[21] ADEA, "Delivering education at home in African member states amid the Covid-19 pandemic," Country status report. Association for the Development of Education in Africa, ADEA. Tunis, Tunisia., 2020. http://www.adeanet.org/en/publications/delivering-education-home-african-member-states-amid-covid-19-pandemic-countrystatus.

[22] T. A. Amorighoye, "COVID-19 has exposed the education divide in Nigeria. This is how we can close it.," 2020. https://www.weforum.org/agenda/2020/06/education-nigeria-covid19-digital-divide/.

[23] D. Mhlanga and T. Moloi, "COVID-19 and the digital transformation of education: What are we learning on 4ir in South Africa?," Education Sciences, vol. 10, no. 7, 2020, doi: 10.3390/educsci10070180.

[24] D. K. Ahorsu, C. Y. Lin, V. Imani, M. Saffari, M. D. Griffiths, and A. H. Pakpour, "The Fear of COVID-19 Scale: Development and Initial Validation," International Journal of Mental Health and Addiction, 2020, doi: 10.1007/s11469-02000270-8.

[25] A. B. Sakpere, M. S. Nkwo, A. M. Abdullahi, M. S. Adamu, and R. Orji, "Age Differences in Problematic Mobile Phone Usage among Africans," In 3rd African Human-Computer Interaction Conference (AfriCHI 2021), March 08-12, 2021, Maputo, Mozambique. 10 pages, doi: https://doi.org/10.1145/3448696.3448705 ACM, New York, NY, USA., 2021.

[26] P. F. Lovibond and S. H. Lovibond, "The structure of negative emotional states: Comparison of the Depression Anxiety Stress Scales (DASS) with the Beck Depression and Anxiety Inventories," Behaviour Research and Therapy, vol. 33, no. 3, pp. 335343, 1995, doi: 10.1016/0005-7967(94)00075-U.

[27] A. B. Sakpere, I. Olanipekun, W. Sakpere, and I. A. Ige, "Work Productivity in the Period of COVID-19 Pandemic and Lockdown: A Developing World Perspective," Nigerian Academy of Science (Special Edition on COVID-19), vol. 13, no. 1s, pp. 1-14, 2020.

[28] O. H. Ajilore, L. E. Malaka, A. B. Sakpere, and A. G. Oluwadebi, "Interactive Survey Design Using Pidgin and GIFS,” In 3rd African Human-Computer Interaction Conference (AfriCHI 2021), March 08-12, 2021, Maputo, Mozambique. 13 pages .doi: https://doi.org/10.1145/3448696.3448701, ACM, 2021.

[29] A. B. Sakpere, "User-defined privacy preferences for k-anonymization in electronic crime reporting systems for developing nations," In proceedings of the 1st International Doctoral Symposium on Security and Privacy. Angers, France. SCITEPRESS (Science and Technology Publications, Lda.), 2015, pp. 13-18.

[30] L. Underhill and D. Bradfield, Introstat. Juta and Company Ltd. Reprint, 2008., 1996.

[31] S. Das and R. M. Rahman, "Application of ordinal logistic regression analysis in determining risk factors of child malnutrition in Bangladesh," Nutrition Journal, vol. 10, no. 1, pp. 1-11, 2011, doi: 10.1186/1475-2891-10-124.

[32] Minitab, "Minitab Manual," 2018. https://support.minitab.com/en-us/minitab/18/help-and-how-to/modelingstatistics/regression/how-to/ordinal-logistic-regression/methods-and-formulas/methods-and-formulas/ (accessed Mar. 29, 2021).

[33] W. Cao et al., "The psychological impact of the COVID-19 epidemic on college students in China," Psychiatry Research, 2020, doi: 10.1016/j.psychres.2020.112934.

[34] A. B. Sakpere, "Using social platforms to increase engagement in teaching computer programming," In Extended Abstracts of the 2019 CHI Conference on Human Factors in Computing Systems 2019, pp. 1-6, ACM. doi: 10.1145/3290607.3313085. 
[35] G. Ssekakubo, H. Suleman, and G. Marsden, "Issues of adoption: Have e-learning management systems fulfilled their potential in developing countries?," In Proceedings of the South African Institute of Computer Scientists and Information Technologists conference on knowledge, innovation and leadership in a diverse, multidisciplinary environment 2011, ACM. doi: $10.1145 / 2072221.2072248$.

[36] M. S. Adamu, "Rethinking Technology Design and Deployment in Africa: Lessons from an African Standpoint," In 3rd African Human-Computer Interaction Conference (AfriCHI 2021), March 08-12, 2021, Maputo, Mozambique. 9 pages. ISBN:978-1-4503-8869-6/21/03, ACM, New York, NY, USA, 2021.

[37] M. M. Hassan and T. Mirza, "The Digital Literacy in Teachers of the Schools of Rajouri (J\&K)-India: Teachers Perspective," International Journal of Education and Management Engineering, vol. 11, no. 1, pp. 28-40, 2021, doi: 10.5815/ijeme.2021.01.04.

[38] M. W. Hassan, M. M., Mirza, T., \& Hussain, "A critical review by teachers on the online teaching-learning during the COVID19.," International Journal of Education and Management Engineering, vol. 10, no. 8, pp. 17-27, 2020.

[39] A. Ugoni and B. F. Walker, "The Chi square test: an introduction.," COMSIG review, vol. 4, no. 3, p. $61,1995$.

[40] F. E. J. Harrel, Ordinal Logistic Regression. Springer, Cham., 2015.

[41] A. Sumner, C. Hoy, and E. Ortiz-Juarez, "Estimates of the impact of COVID-19 on global poverty," UNU WIDER Working Paper 2020/43, 2020.

\section{Authors' Profiles}

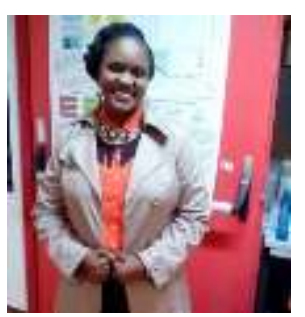

Aderonke Busayo Sakpere holds a PhD in Computer Science from the University of Cape Town, South Africa. She is currently a lecturer at the University of Ibadan, Nigeria. Her research interest is in ICT for Development (Educational Technology, Human Computer Interaction and Data Science/Privacy). She has been working actively on proffering solutions to the COVID-19 pandemic in Africa since May 2020 when she took part in the MIT COVID-19 Hackathon for Africa. Since then, she has continued to expand her research on COVID-19 and has published some of her findings. The most recent of her research on COVID-19 is centered on studying the psychosocial impact of the pandemic on students of tertiary institutions in Nigeria.

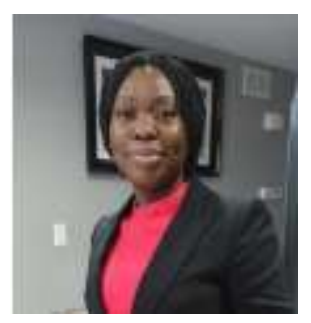

Dr. Ayomiposi Grace Oluwadebi is a Geoscientist with over 9 years of academic experience in teaching and research. She holds a Doctorate degree in Petroleum Geosciences from the University of Manchester, a master's degree from the University of Twente, the Netherlands in Geo-information Sciences and Earth Observation and a bachelor's degree in Geology from the University of Ilorin. She is a Lecturer at the Geological Sciences Department, Osun State University, Nigeria and served as a part-time Teaching Assistant at the University of Manchester, United Kingdom. Dr Grace Oluwadebi have scientific publications and has co-authored articles in high impact journals. Grace is interested in interdisciplinary research such as the COVID-19 research and currently a part of the research team studying Gender-Based Violence in Primary Schools in Nigeria. She is a member of several professional bodies such as the Association of American Petroleum Geologist (AAPG), European Association of Geoscientists and Engineers (EAGE), Association of Women Geoscientist (AWG), Graduate Women International (GWI) among others.

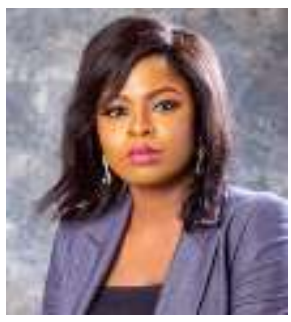

Oluwatoyin Ajilore is an Assistant Lecturer in the Department of Geology, University of Ibadan, Nigeria. Her research interests lie in the areas of Geoscience/Science Education, Economic Geology and Mineral Exploration. She holds a bachelor's degree in Geology (First Class Honor) and master's degree in Mineral Exploration/Economic Geology from the University of Ibadan, Nigeria. She also holds a second master's degree in Mineral Exploration Geosciences from the Pan African University of Life and Earth Sciences (PAULESI) as an African Union Scholar. Oluwatoyin has co-authored articles in conferences and journals and is currently on a pioneer Geoscience Education Research project in Nigeria. She is a member of professional bodies such as Nigerian Mining and Geoscience Society (NMGS) and Jean Piaget Society (JPS). Email: olutoyinajilore@gmail.com

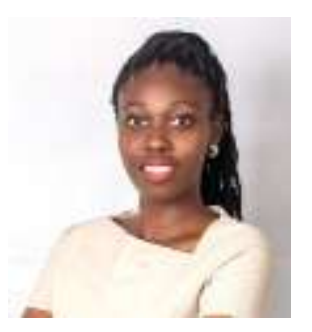

Lauretta Eloho Malaka holds an MSc in Environmental Engineering from the University of Ibadan. She is currently the Program Manager of the TL First Leadership Academy. Her research interest is in Waste management, Education policy and Youth development. 
How to cite this paper: Aderonke B. Sakpere, Ayomiposi G. Oluwadebi, Oluwatoyin H. Ajilore, Lauretta E. Malaka, " The Impact of COVID-19 on the Academic Performance of Students: A Psychosocial Study Using Association and Regression Model", International Journal of Education and Management Engineering (IJEME), Vol.11, No.5, pp. 32-45, 2021. DOI: 10.5815/ijeme.2021.05.04 